\section{Upcoming Journal of Materials Research to Feature High $T_{c}$ Superconductors}

The sixth issue of Journal of Materials Research in 1987 will feature a special section of original research articles on high $T_{c}$ superconductors. A call for papers was issued in May, requesting articles focusing on new results in materials aspects of high $T_{c}$ superconductors, and the articles accepted for publication in this issue offer further insights into this rapidly developing field. The following is a partial list of high $T_{c}$ superconductor articles expected to appear in the November/December issue: - Elastic Constants and Debye Temperature of Polycrystalline $\mathrm{Y}_{1} \mathrm{Ba}_{2} \mathrm{Cu}_{3} \mathrm{O}_{7-x}$, by H.M. Ledbetter, M.W. Austin, S.A. Kim, and M. Lei.

- EPR Assessment of the Electronic Charge of $\mathrm{Cu}$ in $\mathrm{YBa}_{2} \mathrm{Cu}_{3} \mathrm{O}_{7-\delta}$, by S. Benakki, E. Christoffel, A. Goltzene, B. Meyer, C. Schwab, M.J. Besnus, A. Meyer, S. Vilminot, and M. Drillon.

- Fabrication of Oxide Superconductors from Multilayered Metallic Thin Films, by M. Nastasi, P.N. Arendt, J.R. Tesmer, C.J. Maggiore, R.C. Cordi, D.L. Bish, J.D. Thompson, S-W. Cheong, N. Bordes, J.F. Smith, and I.D. Raistrick.

- Thermodynamic Study at High Temperature of the Superconducting System $\mathrm{YBa}_{2} \mathrm{Cu}_{3} \mathrm{O}_{2}$ with $6<\mathrm{z}<7$, by J.F. Marucco, C. Noguera, P. Garoche, and G. Collin. - Magnetic and Electronic Properties of $\mathrm{M}-\mathrm{Ba}-\mathrm{Cu}-\mathrm{O}(\mathrm{M}=\mathrm{Y}, \mathrm{Er}, \mathrm{Eu})$, by $\mathrm{H}$. Jenny, B. Walz, G. Leemann, V. Geiser, S. Jost, T. Frey, and H-J. Güntherodt.

- Magnetization Studies of the High $T_{c}$
Compound $\mathrm{Y}_{1} \mathrm{Ba}_{2} \mathrm{Cu}_{3} \mathrm{O}_{z}$, by J.R. Thompson, D.K. Christen, S.T. Sekula, J. Brynestad, and Y.C. Kim.

- Mechanisms of High $T_{c}$ Superconductivity in Low Dimensional Materials, by V.Z. Kresin.

- Microstructural Characterization of $\mathrm{YBa}_{2} \mathrm{Cu}_{3} \mathrm{O}_{7-x}$, by M. Sarikaya, B.L. Thiel, I.A. Aksay, W.J. Weber, and W.S. Frydrych.

- Oxygen Content, Microstructure and Superconductivity of $\mathrm{YBa}_{2} \mathrm{Cu}_{3} \mathrm{O}_{7-x}$, by M.P.A. Viegers, D.M. de Leeuw, C.A.H.A. Mutsaers, H.A.M. van Hal, H.C.A. Smoorenburg, J.H.T. Hengst, J.W.C. de Vries, and P.C. Zalm.

- Phase Relations in Pseudobinary $\mathrm{Ba}_{2} \mathrm{MCu}_{3} \mathrm{O}_{6.5+x}(\mathrm{M}=\mathrm{Y}, \mathrm{Gd})$, by J. Hauck, $\mathrm{K}$. Bickmann, and F. Zucht.

- Pressure Dependence of the Superconducting Transition Temperatures in $\mathrm{La}_{1.85} \mathrm{Sr}_{0.15} \mathrm{CuO}_{4}$ to $8 \mathrm{GPa}$, by D. Erskine, E. Hess, P.Y. Yu, and A.M. Stacy.

- Reoxygenation of Vacuum Annealed $\mathrm{YBa}_{2} \mathrm{Cu}_{3} \mathrm{O}_{6.9}$, by D.S. Ginley, P.J. Nigrey, E.L. Venturini, B. Morosin, and J.F. Kwak. - Shear-Modulus Change Below $T_{c}$ in $\mathrm{YBa}_{2} \mathrm{Cu}_{3} \mathrm{O}_{7-x}$, by H.M. Ledbetter, M.W. Austin, S.A. Kim, T. Datta, and C.E. Violet.

- The Role of Boundaries in the Superconducting Properties of Sintered $\mathrm{YBa}_{2} \mathrm{Cu}_{3} \mathrm{O}_{7-x}$, by R.A. Camps, J.E. Evetts, B.A. Glowacki, S.B. Newcomb, and W.M. Stobbs.

- Thin Film Synthesis of the High- $T_{c}$ Oxide Superconductor $\mathrm{YBa}_{2} \mathrm{Cu}_{3} \mathrm{O}_{7}$ by Electron Beam Codeposition, by $M$. Naito, R.H. Hammond, B. Oh, M.R. Hahn, J.W.P. Hsu, P. Rosenthal, A.F. Marshall, M.R. Beasley, T.H. Geballe, and A.
Kapitulnik.

- X-Ray Photoemission Spectroscopy of the $90 \mathrm{~K}$ Superconductor $\mathrm{Ba}_{2} \mathrm{YCu}_{3} \mathrm{O}_{7-\delta}$, by Z. Iqbal, E. Leone, R. Chin, A.J. Signorelli, A. Bose, and $\mathrm{H}$. Eckhardt.

In addition to high $T_{c}$ superconductor articles, the November/December issue of Journal of Materials Research will also contain articles on glasses, alloys, polymers, and semiconductors. The following is a partial list of other articles scheduled for the November/December issue:

- 193-nm Excimer Laser-Assisted Etching of Polysilicon, by M.D. Armacost, S.V. Babu, S.V. Nguyen, and J.F. Rembetski.

- Crystallinity of rf-Sputtered $\mathrm{MoS}_{2}$ Films, by J.R. Lince and P.D. Fleischauer.

- Erosion of Amorphous NickelPhosphorus, by K.C. Goretta, J.L. Routbort, A. Mayer, and R.B. Schwarz.

- Fluoropolymer Barriers to Stress Corrosion in Optical Fibers, by L. Klinger and J.R. Griffith.

- Graphite-Alkali Metal-Heavy Metal Ternary Compounds: Synthesis, Structure and Superconductivity, by P. Lagrange.

- Hydration Phase Transitions and Magnetic Properties of Vermiculite Intercalation Compounds, by N. Wada, M. Suzuki, D.R. Hines, K. Koga, and H. Nishihara.

- In-Situ Capacitance Studies of Thin Polymer Films During Compressed Fluid Extraction, by D.H. Ziger.

- Interaction of a $10 \mathrm{eV}$ Silicon Beam with the Si(111) Surface: A Molecular Dynamics Study, by B.W. Dodson and P.A. Taylor. - Kinetics of Surface Area Changes in Glass-Like Carbon: Reanalysis of the Data, by J. Lachter and R.H. Bragg.

- Luminescent Properties of X-Irradiated Rare-Earth-Doped Barium Copper Oxides, by D.W. Cooke, H. Rempp, Z. Fisk, J.L. Smith, and M.S. Jahan.

- Optical Transmission of Graphite and Potassium Graphite Intercalation Compounds, by J.M. Zhang and P.C. Eklund. - Precipitation Phenomena in High Dose Iron Implanted Silica and Annealing Behavior, by A. Perez, M. Treilleux, T. Capra, and D. Griscom.

- Raman Microprobe Measurements of Residual Strains at the Interfaces of Si on Quartz, by Y.M. Cheong, H.L. Marcus, and F. Adar

- Structures and Physical Properties of Carbon Fibers from Coal Tar Mesophase Pitch, by T. Hamada, T. Nishida, Y. Sajiki, M. Matsumoto, and M. Endo.

- The Solidification of Aluminum Manganese Powders, by B.A. Mueller, R.J. Schaefer, and J.H. Perepezko.

- Transformation Toughening of GlassCeramics, by D.R. Clarke and B. Schwartz.

Copies of this issue will be available at the MRS Fall Meeting in Boston. 


\section{How doyou make a fast decisionwhenyourpeople are all over the

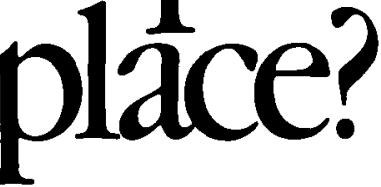

Say you're Johin Licardi, a research scientist specializing in high-temperature superconductivity.

\section{AT\&'Tcomes through for John Licardi with AT\&TALLIANCE Teleconferencing Service.}

It's quite possible youre on the brink of a major break through.

Only problem is, none of your. colleagues are around to help you confirm it. One's at a conference 3,000 miles away, one's on vacation and the other's away giving a lecture.

And you need to confirm your discovery as quickly as possible or a competitor will beat you to it.

Enter AT\&T ALLIANCE ${ }^{\oplus}$ Teleconferencing Service. It allows you to pick up your touch-tone phone and make a conference call by dialing 0700 456-1000**

And the sound is so crystal-clear, you feel like it's all taking place in the same room.

Yet you never left your desk.

You don't need any special equipment, just a touch-tone phone.

Or, if you prefer, you can have an AT\&T operator set up the call for you, just by

dialing 1800 544-6363.

Either way, you're getting the reliability of AT\&T Long Distance working for you.

To use AT\&T ALLIANCE Teleconferencing Service to set up your own conference call, just dial 0700 456-1000.

And follow the step-by-step instructions you'll get over the phone.

From equipment to networking, from computers to communications, AT\&T is the right choice.

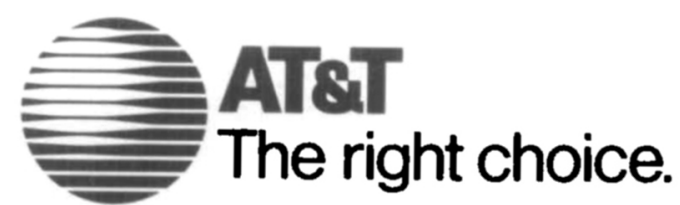

